\title{
Body composition changes of crossbred Holstein $\times$ Gyr cows and conceptus during pregnancy
}

\author{
Anna L. L. Sguizzato, ${ }^{1} \odot$ Marcos I. Marcondes, ${ }^{1} \odot$ Sebastião C. Valadares Filho, ${ }^{1}$ Joel Caton, ${ }^{2}$ \\ Tammi L. Neville, ${ }^{2}$ ๑ Fernanda S. Machado, ${ }^{3} \odot$ Marcos V. C. Pacheco, ${ }^{1}$ and Polyana P. Rotta ${ }^{1 *} \odot$ \\ ${ }^{1}$ Department of Animal Science, Universidade Federal de Viçosa, 36570-000 Viçosa, Minas Gerais, Brazil \\ ${ }^{2}$ Department of Animal Science, North Dakota State University, Fargo 58105 \\ ${ }^{3}$ Embrapa Gado de Leite, 36038-330 Juiz de Fora, Minas Gerais, Brazil
}

\begin{abstract}
This study aimed to evaluate the effects of plane of nutrition and advancing days of pregnancy (DP) on maternal body composition and fetal development. Differing planes of nutrition were established by 2 feeding regimens (FR): ad libitum (AL) or maintenance (MA). Sixty-two nonlactating multiparous Holstein $\times$ Gyr cows with average body weight of $480 \pm 10.1 \mathrm{~kg}$ and an age of $5 \pm 0.5 \mathrm{yr}$ were used. Cows were divided into 3 groups: pregnant $(\mathrm{n}=44)$, nonpregnant $(\mathrm{n}=12)$, and baseline reference cows $(\mathrm{n}=6)$. The 56 pregnant and nonpregnant cows were randomly allocated into 2 different FR: AL or MA. Cows fed at MA received $1.15 \%$ of their body weight on a dry matter (DM) basis, receiving corn silage and a concentrate-based diet at a ratio of $93: 7$ on a DM basis. Reference group cows were slaughtered at the beginning of the experimental period to estimate body composition and empty body weight. To evaluate the effects of DP, pregnant and nonpregnant animals were slaughtered at d 140, 200, 240, and 270 of gestation. Feeding regimen affected maternal tissue composition. Days of pregnancy affected fresh weight (FW), DM, and energy content, but no differences were observed for crude protein $(\mathrm{CP})$ and ether extract (EE) because of DP. Feeding regimen affected mammary gland components (CP, EE, and energy content), but not fresh or dry weights. Days of pregnancy influenced almost all mammary gland components except energy content. Regarding the uterus, FR affected only fresh and dry weights; however, DP affected every uterus component measured. The only interaction between FR and DP in this study was observed for placental FW. Cows fed AL on d 270 presented the same placental FW as cows at MA and $\mathrm{AL}$ on d 200
\end{abstract}

Received August 23, 2019.

Accepted November 22, 2019.

*Corresponding author: polyana.rotta@ufv.br and 240. Further, pregnant cows fed at MA on d 270 had greater placental FW than cows fed AL at this day. Days of pregnancy, but not FR, influenced the composition of fetal fluids in pregnant cows. Finally, cows fed at MA had greater FW for the fetus than cows fed AL; however, fetus composition changed over DP. The FW, DM, EE, and energy content increased until d 270, but CP decreased. In conclusion, the novelty of our data presents how changes due to FR and DP occur in maternal tissues and the conceptus.

Key words: gravid uterus, maternal tissue, nutrient deposition, pregnancy

\section{INTRODUCTION}

Pregnancy and lactation are high-priority functions that increase nutrient demand (Bauman and Currie, 1980). During the final third of gestation, the developing gravid uterus and the mammary gland receive a greater partitioning of nutrients to maintain their demand for tissue growth and accelerated metabolic rate, even at the cow's expense (Bell, 1995; Van Eetvelde et al., 2016). The changes in metabolic rates of the gravid uterus and mammary gland tissues may generate enormous challenges to the cow, leading to early postpartum health problems and compromising lactation performance (Bell, 1995).

According to Bauman and Currie (1980), partitioning of nutrients to body tissues involves 2 types of regulation: homeostasis and homeorhesis. Homeostasis is the capability to maintain a physiological equilibrium or constant condition (or both) in the internal environment. The second type of regulation, homeorhesis, accounts for coordinated changes in metabolism of body tissue necessary to support a physiological state (Bauman and Currie, 1980), which is intrinsically related to pregnancy changes in a body.

To understand how alterations may occur during pregnancy, it is necessary to evaluate and estimate maternal body composition (Ferrell et al., 1976a). 
Therefore, the importance of obtaining data related to prenatal growth and tissue development during gestation is evident to better assess the quality and quantity of nutrients required to maintain pregnancy (Ferrell et al., 1976b; Bell, 1995; Vonnahme et al., 2018).

Nonetheless, a limited number of studies have evaluated compositional changes during pregnancy. To our knowledge, Ferrell et al. (1976a), Andrew et al. (1994), and Bell (1995) are the only authors to study the characteristics of these changes in the cow body, mammary gland, and gravid uterus. These authors were able to explain how nutrient absorption happens and how nutrient deposition takes place. However, to completely understand how the gestational process influences growth and requirements of pregnant cows, the following questions need to be addressed: What is the pattern of tissue deposition regarding fat and protein in pregnant cows? How do these components change over the lactation? Should differences in nutrition be considered while evaluating nutrient requirements for pregnant cows? Does feeding regimen affect maternal and fetal development? Research addressing these questions will provide a new perspective and allow a better understanding of changes related to maternal and conceptus body composition during pregnancy.

Therefore, this research aimed to evaluate changes in maternal body composition and fetus development during different days of pregnancy (DP) when provided differing feeding regimens (FR): ad libitum (AL) or maintenance (MA). We hypothesized that cows fed AL will present greater fat deposition when compared with that for cows fed at MA, which will directly affect fetus development and tissue deposition from mid-gestation to calving.

\section{MATERIALS AND METHODS}

This study was conducted at Universidade Federal de Viçosa (Viçosa, MG, Brazil) following the standard procedures for humane animal care and handling according to the university's guidelines $(47 / 2012)$.

Study data are from a previous experiment conducted by Rotta et al. (2015a,b,c). Briefly, 62 Holstein $\times$ Gyr cows with an average initial weight of $480 \pm$ $10.1 \mathrm{~kg}$ and $5 \pm 0.5 \mathrm{yr}( \pm \mathrm{SD})$ were used. They were divided into 2 treatment groups, according to FR: AL and MA (1.15\% of BW). We used the value of $1.15 \%$ of BW for the MA group according to a previous study (Duarte et al., 2013). The nutritional model used to determine cow's requirement was the NRC (2001), and we expected ADG of $1.0 \mathrm{~kg}$ for AL cows and $0.1 \mathrm{~kg}$ for MA cows. Diet was composed basically by corn silage, cotton meal, urea, mineral mixture, and vitamins, with a concentrate-based diet at a ratio of $93: 7$ on a DM basis. Feed was delivered twice daily, $60 \%$ in the morning and $40 \%$ in the afternoon. To allow AL cows ad libitum access to feed, feed delivery was adjusted to allow approximately $5 \%$ orts daily on an as-fed basis. A detailed description of the experimental diet and management is available in Rotta et al. (2015c). The average milk production from the previous lactation of $\mathrm{AL}$ and MA cows were $12.1 \pm 1.25$ and $12.8 \pm 1.11$ $\mathrm{L} / \mathrm{d}$, respectively, in a pasture-base system. Ad libitum and MA cows had $2.7 \pm 0.20$ and $2.8 \pm 0.16$ lactations, respectively.

The animals were divided into 3 groups: pregnant $(\mathrm{n}=44)$, nonpregnant $(\mathrm{n}=12)$, and baseline $(\mathrm{n}=6)$. Baseline cows were slaughtered at d 0 . The 44 pregnant cows were slaughtered at 4 different DP: d 140, 200, 240 , and 270. However, 1 abortion was verified in a cow from the MA treatment at d 140. Thus, data from 43 cows were used for analyses, and 5 MA cows were evaluated at d 140 of pregnancy. The 12 nonpregnant cows were slaughtered at d 200, 240, and 270. Figure 1 illustrates the experimental scheme, FR, and slaughter.

For all comparisons between nonpregnant and pregnant animals, and among pregnancy groups, nonpregnant cows were included as DP 0; animals slaughter between DP 137 and 144 were included in the model as d 140. Animals slaughtered between DP 196 and 201 were included in the model as d 200, and animals slaughtered between DP 236 and 247 were included in the model as d 240. Last, animals slaughtered between DP 266 and 270 were included in the model as d 270.

Cows were slaughtered at Universidade Federal de Viçosa by captive bolt stunning followed by exsanguination. Immediately after exsanguination, the gravid uterus, composed of uterus, placenta, fetus, and fetal fluids, was sectioned at cervix height and dissected. Then it was immediately collected and weighed. Weight of fetal fluids was obtained by difference between gravid uterus minus fetus, fetal membranes, and uterus. Fetus, fetal membranes, uterus, and mammary gland were individually ground and sampled. Then a homogenized sample was created with the uterus and fetal membranes. Samples from gravid uterus and mammary gland were maintained at $-80^{\circ} \mathrm{C}$ until further analyses. The initial colostrum produced by cows at the end of gestation was not removed from the mammary gland. Thus, colostrum was accounted for as part of mammary gland weight and composition, obtained from animals slaughtered at DP 270.

Sampling after slaughtering extended to carcass and noncarcass components. Carcasses were divided into 2 halves, and the left half of carcass was weighed and chilled at $4^{\circ} \mathrm{C}$ for $24 \mathrm{~h}$. Carcass was composed of 


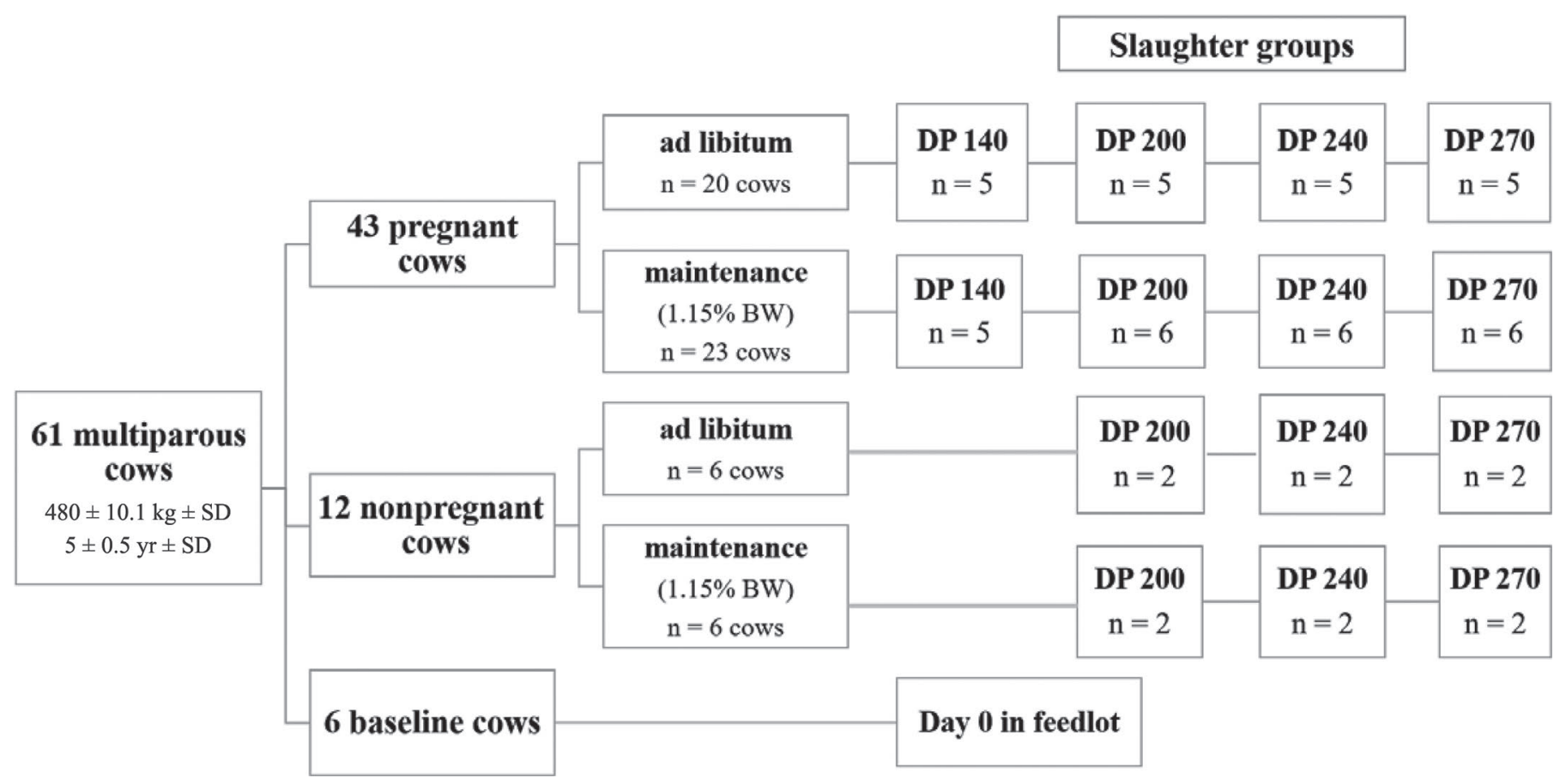

Figure 1. Experimental scheme, feeding regimen, and slaughter groups. DP = days of pregnancy.

bones and meat cuts from half carcasses. Further, to compose the noncarcass sample, the following tissues were collected: the 4 stomachs and small and large intestines, internal organs, head, tail, hooves, trimmings, hide, and blood. Stomachs and intestines were washed after slaughter; then, all components were ground, homogenized, and sampled. Maternal tissue (MT) was composed of the sum of the carcass and noncarcass components.

Samples of carcass, noncarcass, mammary gland, uterus, placenta, fetal fluids, and fetus were analyzed for DM (AOAC International, 2000; method 934.01), CP (AOAC International, 2000; method 981.10), ether extract (EE; AOAC International, 2006; method 945.16), and energy content using the equation proposed by ARC (1980). Values obtained for body components were calculated as the sum of fresh weight $(\mathbf{F W}), \mathrm{DM}, \mathrm{CP}, \mathrm{EE}$, and energy content. Fresh weight content (Tables 1 and 2) was calculated as a percentage of empty body weight (EBW). Dry matter content was calculated as percentage of FW. In addtion, CP, and EE were obtained as a percentage of DM and finally, energy content was calculated as the amount of energy (Mcal) in EBW (kg). Values of FW, DM, CP, and EE are presented as a percentage, and values for energy are presented as megacalories per kilogram. More details about management and laboratory analyses are available in Rotta et al. (2015a,b,c).
Data on MT, mammary gland, uterus, and components of gravid uterus were evaluated as a completely randomized design with a factorial arrangement $2 \times$ 5, 2 FR (MA and AL) and 5 DP (0, 140, 200, 240, and 270), using PROC GLIMMIX of SAS (version 9.4; SAS Institute Inc., Cary, NC). It is important to highlight that a DP of 0 refers to nonpregnant animals. All variables had normal distribution according to the Shapiro-Wilk test. Degrees of freedom were corrected using the Kenward-Roger approximation. When an effect of DP was observed, Student's $t$-test was used to compare least squares means. In the absence of interactions, the main effects of FR and DP are discussed. For all analyses, significance was declared when $P<0.05$.

\section{RESULTS AND DISCUSSION}

\section{Carcass and Noncarcass Composition}

No interaction $(P>0.05$; Table 1$)$ between FR and DP was observed for carcass and noncarcass components of FW, DM, CP, EE, and energy content. Feeding regimen did not affect $(P=0.146) \mathrm{FW}$ of carcass; however, it affected DM, CP, EE, and energy content. Animals fed AL present greater $(P=0.001)$ DM content than MA animals. On the other hand, MA cows had greater $(P=0.001)$ content of CP. In addition, MA cows also presented a lower $(P=0.001)$ percentage of 


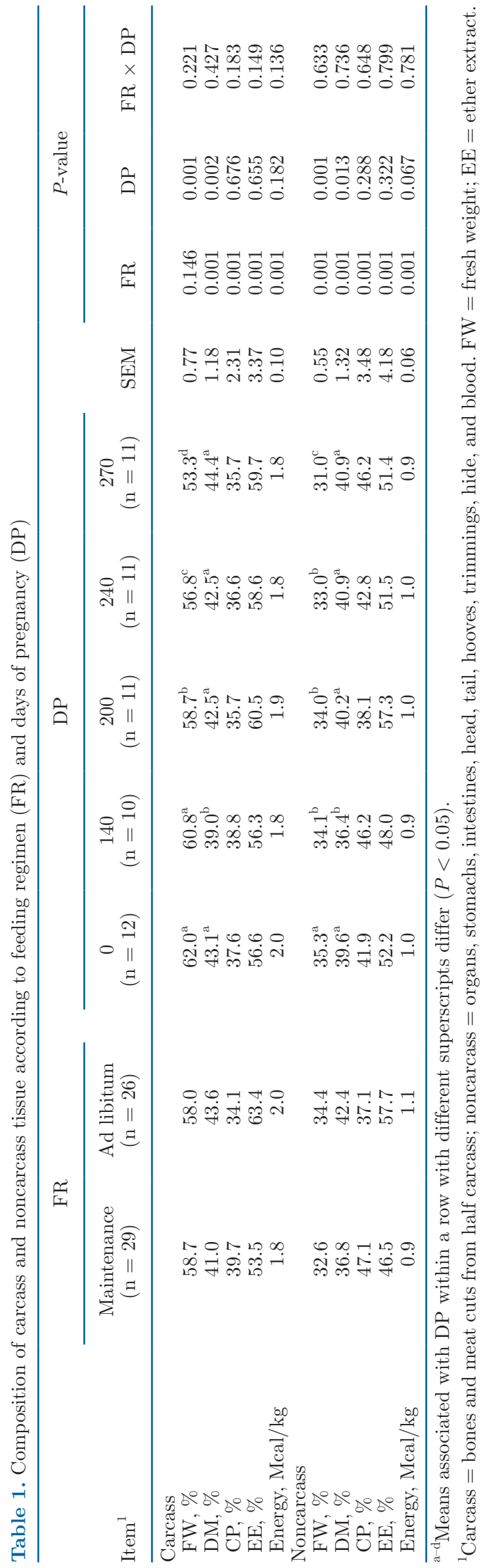

EE when compared with cows fed AL, followed by a lower $(P=0.001)$ content of energy.

The DP affected FW and DM content $(P=0.001$ and $P=0.002$, respectively; Table 1$)$. Nevertheless, DP did not affect $(P>0.05) \mathrm{CP}, \mathrm{EE}$, or energy content. Fresh weight decreased as DP increased $(P=0.001)$, without differences $(P=0.123)$ for $\mathrm{d} 0$ and 140 , with d 0 referring to nonpregnant cows. These values decreased $2 \%$ on d 200, and further decreased by an additional 2 and $3 \%$ on d 240 and 270, respectively (Table 1). During pregnancy, cows mobilized almost $9 \%$ of their FW content. The DM content was different $(P=0.002)$ from $\mathrm{d}$ 0 to $140(4 \%)$, followed by an increase $(P=0.008)$ on d 200 until the end of pregnancy.

Feeding regimen affected all noncarcass components $(P=0.001$; Table 1$)$. Cows fed AL had greater contents of FW, DM, EE, and energy content. However, $\mathrm{CP}$ percentage was greater for cows fed at MA. Days of pregnancy affected $\mathrm{FW}(P=0.001)$ and $\mathrm{DM}(P$ $=0.013)$ of noncarcass components. Fresh weight decreased $(P=0.042)$ on d 140; however, it remained the same $(P=0.058$; Table 1$)$ through d 140,200 , and 240 , followed by another decrease $(P<0.001)$ on $\mathrm{d} 270$. The DM content decreased $(P=0.020)$ on $\mathrm{d} 140$ followed by an increase on d $200(P=0.008$; Table 1$)$, which remained unaltered until the end of pregnancy (Table 1). In addition, noncarcass DM content followed the same pattern as that observed in carcass DM content.

According to our results, we may assume that the increase in DM, EE, and energy content for carcass, and FW, DM, EE, and energy content for noncarcass, reflect the FR offered to these cows. This pattern of constituents is similar to what we can observe in growing and fattening animals (Owens et al., 1995; Nürnberg et al., 1998). Proportionally, the amount of EE and energy content in AL cows correspond to greater proportions of fat stored in both carcass and noncarcass. In contrast, cows at MA probably did not retain more protein, but sustained their amount of CP in carcass and noncarcass tissues and mobilized or maintained their percentage of $\mathrm{EE}$ and energy content, thus reflecting greater percentages of $\mathrm{CP}$.

Changes in FW due to DP may be related to differences in water content since no difference was observed in $\mathrm{CP}, \mathrm{EE}$, or energy content. However, according to Andrew et al. (1994), the amount of water in fat free mass is inversely correlated with the amount of fat. In addition, it is also known that protein has a strong attraction to water molecules. Therefore, in our study, we attribute the reduction in FW because of DP to the increased amount of EE in cows. We could not provide a concise explanation about the decrease observed for DM on d 140. Nevertheless, we address the reduction on DM to changes in the early gestational phase. This 
Sguizzato et al.: CHANGES IN BODY COMPOSITION OF PREGNANT COWS

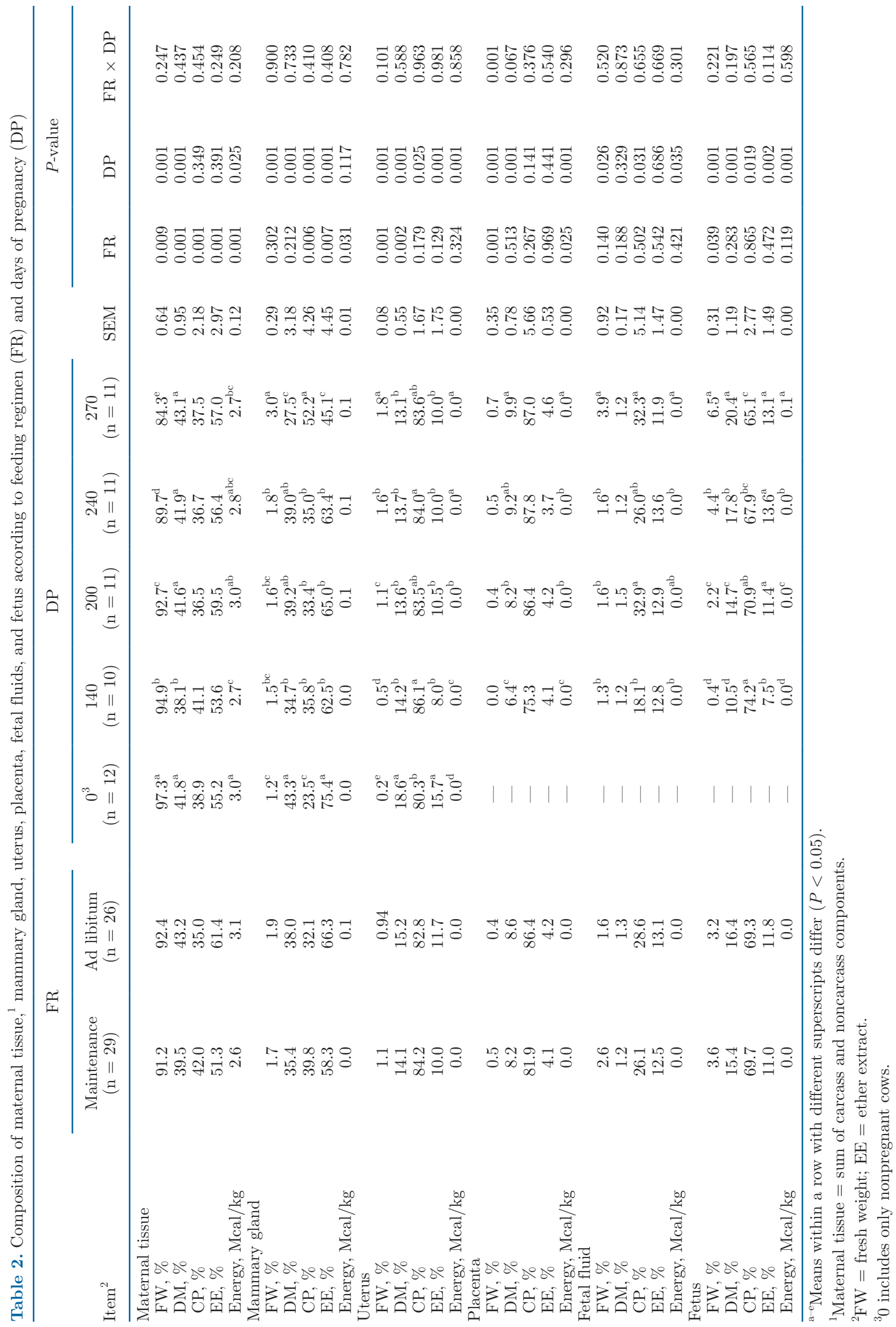


phase consists of crucial changes in maternal physiology, altering hormone concentration and homeostasis, and the effort to maintain pregnancy (Mann et al., 1999; Wiltbank et al., 2016; Yan et al., 2016). In addition, we suggest further investigation on mobilization/ deposition pattern on $\mathrm{FW}$ and $\mathrm{DM}$ content according to DP.

\section{Maternal Tissue Composition}

No interactions between FR and DP were observed for MT composition $(P>0.05$; Table 2$)$. Feeding regimen affected $(P<0.05) \mathrm{FW}, \mathrm{DM}, \mathrm{CP}, \mathrm{EE}$, and energy content. Cows feed AL had greater FW, DM, EE, and energy content when compared with MA animals; however, CP content was greater for MA animals.

Days of pregnancy affected FW $(P=0.001)$, DM $(P$ $=0.001)$, and energy content $(P=0.025)$. However, no difference was observed for $\mathrm{CP}(P=0.349)$ and $\mathrm{EE}(P$ $=0.391)$. Mobilization of FW is observed through pregnancy, becoming more intense during the final third of gestation (Table 2). Dry matter percentage decreased $(P \leq 0.001)$ from d 0 to 140 ; however, increasing deposition of DM $(P \leq 0.001)$ was observed from d 200 until the end of pregnancy (Table 2). Changes in energy content are marked by accretion and mobilization $(P=$ $0.025)$ through pregnancy (Table 2). Crude protein and EE content were not different among DP $(P \geq 0.349$; Table 2).

The lower proportion of $\mathrm{CP}$ in $\mathrm{MT}$ of $\mathrm{AL}$ animals clearly indicates greater amounts EE storage. According to Marcondes et al. (2016), animals achieve mature $\mathrm{BW}$ when their content of EE is about $25 \%$ of $\mathrm{EBW}$. Furthermore, according to Owens et al. (1993), animals that have not achieved their mature weight may deposit less EE as a proportion of weight gain. In our study, animals fed AL had an average of $25 \%$ of EE in EBW; for MA cows EE was closer to 19\%. The average percentage of EE in EBW was calculated by dividing the EE content by EBW of cows in the AL and MA treatment, respectively. Therefore, our results indicate that cows fed AL had lower rates of protein deposition than MA cows. The outcome is attributed to the FR effect, where a greater proportion of feed is consumed in $\mathrm{AL}$ treatment, resulting in greater energy intake. However, lower rates of protein deposited in AL cows also happen because of the ability to deposit greater amounts of $\mathrm{EE}$ in carcass and noncarcass components, which is a maturity weight effect.

Ferrell et al. (1976a) observed that physiological state (pregnant and nonpregnant) did not affect composition of offal, carcass, or EBW when evaluating body composition of pregnant Hereford heifers. However, the pat- tern of body tissue deposition presented by the previous authors does not agree with the pattern of our study, which presented differences on FW of nonpregnant and pregnant cows.

Because MT is the sum of carcass and noncarcass components, as expected, MT changes in FW and DM over DP followed the same pattern. Despite the lower magnitude of values regarding $\mathrm{CP}$ and $\mathrm{EE}$ in MT, which lead to the absence of statistical differences $(P \geq 0.349)$, a numerical difference was observed in percentages of these components due to DP. Nevertheless, when combining $\mathrm{CP}$ and EE to calculate energy content as a percentage of EBW, these numerical differences became significant $(P=0.025)$. Then, a slightly greater value of energy content on MT of nonpregnant cows was observed (Table 2).

In fact, changes in energy content of MT are minimal over DP. Thus, we considered it difficult to obtain greater values of energy contents due to the lower number of animals allocated in each treatment. Therefore, using $5 / 6$ replications per treatment $(\mathrm{FR} \times \mathrm{DP})$ was a limitation due to ethics committee laws and a greater number of pregnant cows would restrict the conduct of this study.

\section{Mammary Gland Composition}

No interaction $(P>0.05)$ was observed between FR and DP for mammary gland composition. Feeding regimen affected $(P=0.006)$ composition of $\mathrm{CP}$ in mammary gland, as well as $\operatorname{EE~}(P=0.007)$ and energy content $(P=0.031$; Table 2$)$. Days of pregnancy affected $(P=0.001) \mathrm{FW}, \mathrm{DM}, \mathrm{CP}$, and EE content in the mammary gland, but no difference was observed for energy content $(P=0.117)$. The greater proportion of $\mathrm{CP}$ is a response to reduced levels of EE content in the mammary gland of MA cows, which also leads to a lower energy content in MA cows.

The effect $(P=0.001)$ of DP on FW and DM observed in our study probably occurred as a response to colostrum production and accumulation. According to Godden (2008) and Castro et al. (2011), colostrum production in ruminants begins several weeks before parturition, even before lactogenesis, with a considerable increase in IgG content in milk secretor cells, 1 to $3 \mathrm{~d}$ before parturition. The immunoglobulin content of colostrum may vary according to some characteristics, including cows age, parity, and breed (Vann et al., 1995; Aydogdu and Guzelbektes, 2018). In addition to the increase in immunoglobulin content, an increase in liquids occurs because part of the colostrum is composed of water. In our study, as already mentioned, cows were about 5 yr old and around their third parity. 
These features may help to explain and reinforce the increase in mammary gland $\mathrm{FW}$ and $\mathrm{DM}$ decrease, according to DP.

Crude protein accretion in the mammary gland because of DP is greater than other components, mainly from d 240 to 270 ( $P \leq 0.001$; Table 2). This $\mathrm{CP}$ accretion in the mammary gland could be considered to be indicative of the mammogenesis process, within ductal branching and alveoli development (Plath et al., 1997; Plath-Gabler et al., 2001; Akers, 2017). On the other hand, an abrupt decrease occurs in EE content in the mammary gland because of DP. It is important to highlight that the average $\mathrm{EE}$ on $\mathrm{d} 0$, referent to nonpregnant cows, is greater $(P=0.007)$ than $\mathrm{d} 140$, 200 , and $240(P \leq 0.020)$, indicating greater levels of $\mathrm{EE}$ in the mammary gland before pregnancy.

In addition to our discussion, we may also infer that the increase in $\mathrm{CP}$ and decrease in $\mathrm{EE}$ through pregnancy are closely related to colostrum production and accumulation in the mammary gland. The protein content of colostrum is greater than in milk (Godden, 2008). Therefore, the rise in CP percentage may also be explained by the increased colostrum production and accumulation, which initiates weeks before parturition. Furthermore, the reduction on EE percentage is explained by its lower value when compared with protein content in colostrum (Godden, 2008). However, some researchers considered that the reduction in fat content in colostrum is inversely related to the number of parities. This finding agrees with our results, once cows were about $5 \mathrm{yr}$ old and in approximately their third lactation.

In a previous study evaluating udder composition of pregnant and nonpregnant heifers, Ferrell et al. (1976b) found an increase in FW, DM, EE, and energy content $(\mathrm{kg})$ at greater feeding levels. They observed an interaction between pregnancy and time in the case; in addition, they observed difference for udder FW. However, they did not observe changes in DM, EE, and energy content related to pregnancy, indicating little effect of the mammary gland on pregnancy requirements.

Our data showed an increase in mammary gland EE due to FR, AL regimen. This result, like Ferrell et al. (1976b), would allow us to question whether this long-term AL regimen would impair future lactation. In addition, changes in $\mathrm{CP}$ and $\mathrm{EE}$ levels because of DP may be indicative of mammary gland requirements within pregnancy requirements.

\section{Uterus Composition}

No interaction for uterine composition measurements was observed for FR and DP $(P>0.05$; Table 2$)$. Feeding regimen affected $\mathrm{FW}$ and $\mathrm{DM}$ in uterus composi- tion $(P=0.001)$. Regarding DP, differences $(P<0.05)$ were observed for all components measured, FW, DM, CP, EE, and energy content (Table 2).

The uterus FW content for cows fed at MA was greater than for cows fed AL. This greater value could be because of a compensatory stimulus from MA cows. Additional information about these characteristics were published by Rotta et al. (2015b), where they also found an increased number of placentomes in MA cows.

Uterine FW becomes greater as DP increase, achieving a percentage of 1.85 of cow's EBW at d 270. This increase is expected because of the natural development of fetus, placenta, and increased fetal fluids. On the other hand, uterus DM does not change according to pregnancy. Indeed, DM content on d 0, nonpregnant cows is greater $(P<0.001)$ than the measurements during pregnancy.

Crude protein increased $(P<0.001)$ from d 0 to 140 followed by a slight and nonsignificant reduction until d 270. According to Bell (1995), an elevated uterine uptake of AA occurs during gestation to supply the pregnancy requirement; however, in the present study, this uptake was only observed until d 140, with a considerable retention of this nutrient until the end of pregnancy $(P=0.025)$. Ferrell et al. (1976b) also observed a similar pattern with heifers, which they attributed to a uterine growth that preceded growth of fetal membranes, supporting the fact that fetal development is dependent on prior development of the uterus and placental modifications (Ferrell et al., 1976b; Greseth et al., 2017a).

Ether extract content in the uterus was greater $(P \leq$ 0.004) for cows on $d 0$ than through DP. Therefore, we could consider that the greater fat content in uterus of nonpregnant cows could be used as an energy source to help in uterus development, since uterine fat content is reduced by d 140 of gestation. In addition, we may consider a dilution effect as the size of the uterus increase and $\mathrm{EE}$ content may remain the same, resulting in a smaller percentage of $\mathrm{EE}$ in the uterus.

\section{Placenta Composition}

An interaction between FR and DP was observed for FW component $(P=0.001)$. Feeding regimen did not affect $(P>0.05) \mathrm{DM}, \mathrm{CP}$, or EE, but affected FW $(P$ $=0.001)$ and energy content $(P=0.025)$. On the other hand, differences because of DP were observed for FW $(P=0.001)$, DM $(P=0.001)$, and energy content $(P$ $=0.001)$. Placenta content of $\mathrm{CP}$ and $\mathrm{EE}$ did not differ according to DP $(P>0.05$; Table 2$)$.

According to interaction results, we observed that cows fed AL or at MA on d 140 presented no differences $(P=0.804)$ on placenta $\mathrm{FW}$; however, placenta $\mathrm{FW}$ 


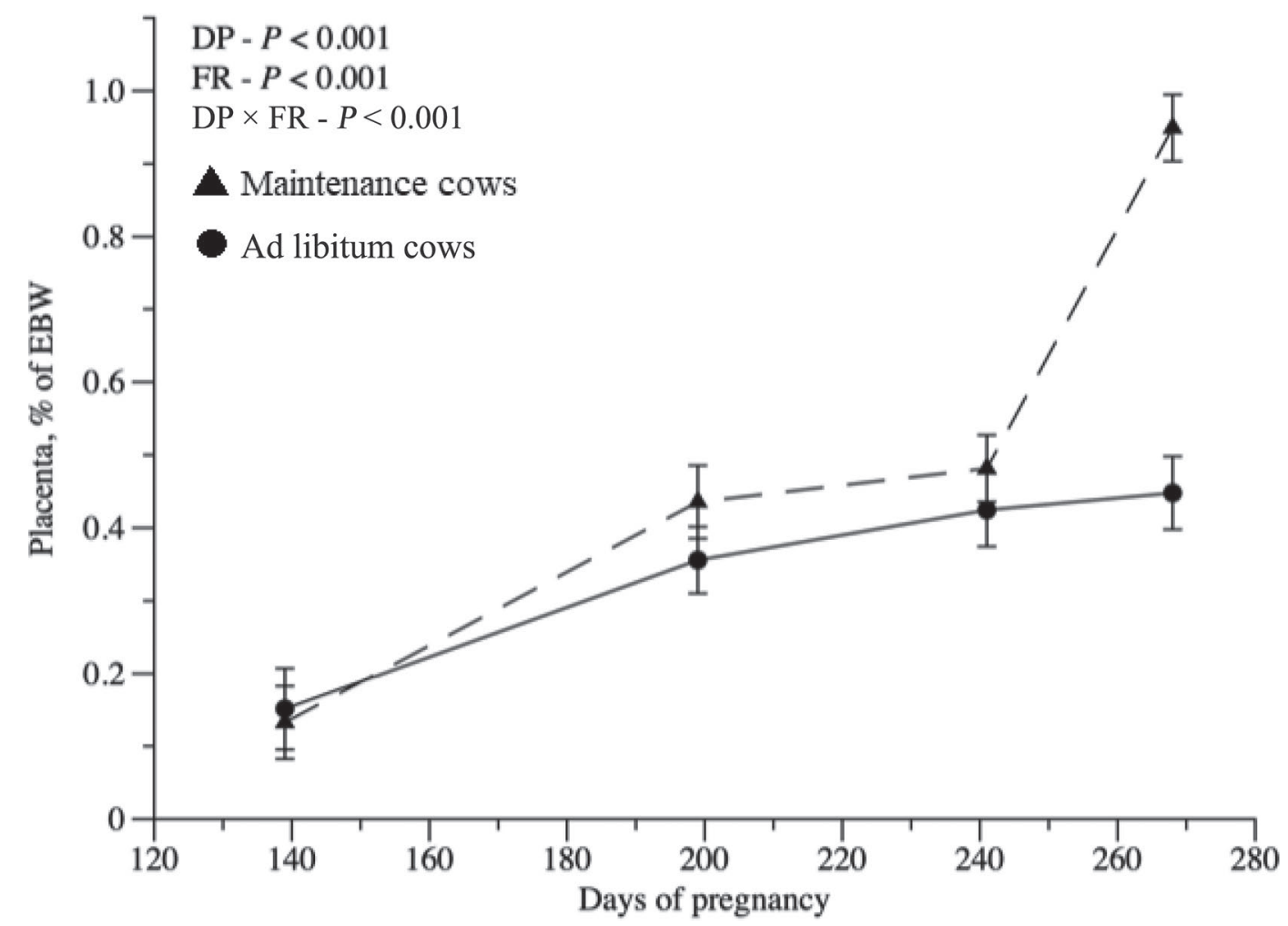

Figure 2. Interaction between feeding regimen (FR) and days of pregnancy (DP) on placental fresh weight (\% EBW) of cows fed at maintenance and ad libitum. Error bars indicate SE.

was lower at d 140 than on d 200, 240, and 270 for both AL and MA cows. Then, from d 200 to 240, cows fed at MA and AL had no differences $(P \geq 0.06)$ on placenta FW. In addition, cows fed AL on $\mathrm{d} 270$ presented the same $(P \geq 0.183)$ placental $\mathrm{FW}$ as cows at $\mathrm{MA}$ and AL on d 200 and 240. Further, pregnant cows fed at MA on d 270 had a greater $(P<0.001)$ placental FW than cows fed AL on this day. Figure 2 provides a clear illustration of this interaction.

The increase in placental FW because of FR and DP may be related to the greater number of placentomes observed for MA animals and because of greater placental vascularization. As reported by Rotta et al. (2015b), cows fed at MA may have an adaption mechanism to supply requirements to the fetus through the placenta without impairing fetal development.

As pointed out by Greseth et al. (2017a), in early gestation fetus survival relies upon nutrient transporters in the utero and the developing placenta, such as fructose and AA transporters. This dependency for nutrient transporters occurs because of the absence of umbilical blood flow, which is not developed in early pregnancy (Greseth et al., 2017b). Therefore, the increase in placental DM through DP observed in our study could be a response to increased requirement for nutrients.

Although the need for nutrients increases through pregnancy, the absence of differences $(P>0.05)$ regarding $\mathrm{CP}$ and $\mathrm{EE}$ in the placenta was noticed. However, we may not infer that no nutrient deposition occurred in the placenta once its FW, DM, and energy content increased $(P=0.001)$ through DP. What we could infer is that nutrients are deposited and used in different forms, and not only as CP and EE. Therefore, a welldeveloped placenta with greater nutrient transporters, vascularity, and greater number of placentomes would be able to allow an appropriate fetal development (Rotta et al., 2015b).

\section{Fetal Fluid Composition}

No interaction between FR and DP was observed in this study $(P>0.05)$. In addition, FR did not influence composition of fetal fluids in pregnant cows $(P>$ $0.05)$. Nevertheless, DP affected FW of fetal fluids $(P$ $=0.026), \mathrm{CP}(P=0.031)$, and energy content $(P=$ $0.035)$. Differences were not observed regarding DP on $\mathrm{DM}(P=0.329)$ and EE $(P=0.686$; Table 2$)$. 
Fetal fluids are substantial for fetal development, because of its physiological and nutritive response (Silva, 2010). These physiological and nutritive responses occur on account of amniotic fluid composition, which include hormones, nutrients, and various solutes that may pass the placenta (Peter, 2013). According to Peter (2013), the volume of these fluids is related to DP and fetal membranes. In our study, the percentage of FW, CP, and energy content in fetal fluids was affected by DP, which agrees with the findings of the 2 authors mentioned above.

A substantial increase of fetal fluid content occurs at the end of pregnancy, approximately 2.5 times the initial average (Table 2). Crude protein content increased $(P=0.009)$ until d 200, remaining the same until $\mathrm{d}$ 270. This increase in CP content converges with fetal development through pregnancy, indicating the need for nutrients such as AA and fructose, which are known as primarily sources of energy used by the fetus (Bell et al., 1992, 1993; Greseth et al., 2017a).

More recent research (Greseth et al., 2017a) reported an increase of fructose in amniotic fluids due to maternal nutritional status and DP (until d 50). They observed greater amounts of fructose at d 34 of cows fed a restricted diet, with a considerable decrease at $\mathrm{d}$ 50. These authors considered these changes in amniotic fluids as a response to an increased demand of nutrients before organogenesis, followed by its reduction. However, in our study, the period in which an increase in fetal fluids occurs is after the organogenesis process (d 140 to 200). Therefore, greater changes happened in our study until d 200, where fetal fluids are responsible for nourishing the fetus. After this period, the placenta is responsible for fetal nutrition, explaining the greater stability in percentage of fetal fluids.

Although we were not able to distinguish between the amniotic and allantoic fluids, Toniollo and Vicente (1995) observed lower amounts of amniotic fluids during the middle third of gestation and a greater volume of allantoic fluids in the initial and final thirds of gestation. Data related to the composition of fluids collected by Toniollo and Vicente (1995) is not available. However, according to data obtained in the current study, the increase of $\mathrm{CP}$ is greater than $\mathrm{EE}$, therefore showing no pattern of accretion of fat. Our results are further sustained by the fact that permeability of fatty acids through the placenta is minimal (Bell et al., 1992).

\section{Fetus Composition}

No interactions were observed between FR and DP $(P>0.05$; Table 2$)$. Feeding regimen only affected FW of fetus $(P=0.039)$, without major changes in other components as published by Rotta et al. (2015b).
Furthermore, DP affected FW $(P=0.001), \mathrm{DM}(P=$ $0.001)$, CP $(P=0.019)$, EE $(P=0.002)$, and energy content $(P=0.001$; Table 2$)$.

Fetal FW of cows fed at MA was greater than for cows fed AL. This considerable difference in fetal FW could be because of adaptations in placenta development of cows fed at MA (Rotta et al., 2015b), providing adequate levels of nutrients to the fetus without compromising development. According to results obtained from the current study, fetal FW increased considerably. Fetal FW achieved an average of $6.5 \%$ of dam EBW at d 270 of gestation (Table 2). Further, the increase in DM and energy content through pregnancy is attributed to the increase in EE content. Moreover, $\mathrm{CP}$ content decreased as pregnancy advanced, and at d 140, CP accounted for $74 \%$ of the DM content and decreased to $65 \%$ of DM content at d 270 . These results do not mean a reduction on CP content, but a possible increase in other components, since DM content was still rising.

Regarding conceptus metabolism, its development is better explained when considering all of conceptus components and the gravid uterus (Bell, 1995). Further, for fetus development, it is essential to consider changes in fetus composition, which occur because of requirement and availability of nutrients. According to Bell (1995), only $32 \%$ of the amino acid $\mathrm{N}$ taken up by the late-gestation fetus is deposited as protein. Therefore, the fetal requirement for metabolizable AA is 3 times the net requirement for fetal growth. Considering data available from our study, to deposit $65 \%$ of $\mathrm{CP}$ in fetal tissues, the fetus would require 3 times more protein from the dam. Therefore, an increased amount of CP would be required to cause changes in fetal composition through pregnancy.

The pattern of EE deposition in the fetus is available in Table 2. An increase of EE concentration was observed from d 140 to $200(P=0.016)$. The amount of EE at d 140 represents 7.5\% of DM content and approximately $13 \%$ at $d 270$. According to Bell (1995), the nutritional requirement for fat deposition in the fetus is relatively small, approximately $5 \%$ of fetal energy requirements. Moreover, there is a reduced deposition of fat in the fetus due to a reduced placenta permeability to fatty acids (short- and long-chain) and ketones (Bell et al., 1993). Therefore, despite the absence of data on composition of the Holstein $\times$ Gyr fetus, the lower percentage of fetal EE observed in our study agrees with information found in the literature.

\section{CONCLUSIONS}

The novelty of our data specifically presents how changes in MT occur as much as changes in the con- 
ceptus. Feeding regimen has an effect on MT and the mammary gland, resulting in accumulation of fat for $\mathrm{AL}$ regimen. In contrast, placenta composition is beneficially affected by the MA regimen. The modifications on MT, mammary gland, and gravid uterus because of DP were partially expected, mainly for the gravid uterus. Nevertheless, new research should focus on these changes to assess and explain what signals are coordinating these modifications and to understand the extension of changes during pregnancy and how they would affect nutritional requirements.

\section{ACKNOWLEDGMENTS}

We are grateful to the following Brazilian foundations for their help with this study: Coordenação de Aperfeiçoamento de Pessoal de Nível Superior (CAPES; Brasilia, DF, Brazil), Conselho Nacional de Desenvolvimento Científico e Tecnológico (CNPq; Brasilia, DF, Brazil), Fundação de Amparo à Pesquisa do Estado de Minas Gerais (FAPEMIG; Belo Horizonte, MG, Brazil), and Instituto de Ciência e Tecnologia de Ciência Animal (INCT-CA; Viçosa, MG, Brazil). The authors have not stated any conflicts of interest.

\section{REFERENCES}

Akers, R. M. 2017. A 100-Year Review: Mammary development and lactation. J. Dairy Sci. 100:10332-10352. https://doi.org/10.3168/ jds.2017-12983.

Andrew, S. M., D. R. Waldo, and R. A. Erdman. 1994. Direct analysis of body composition of dairy cows at three physiological stages. J. Dairy Sci. 77:3022-3033. https://doi.org/10.3168/jds.S0022 $-0302(94) 77244-1$.

AOAC International. 2000. Official Methods of Analysis. 17th ed. AOAC International, Arlington, VA.

AOAC International. 2006. Official Methods of Analysis. 18th ed. AOAC International, Gaithersburg, MD.

ARC (Agricultural Research Council). 1980. The Nutrient Requirements of Ruminants Livestock. CAB International, London, UK.

Aydogdu, U., and H. Guzelbektes. 2018. Effect of colostrum composition on passive calf immunity in primiparous and multiparous dairy cows. J. Vet. Med. 63:1-11. https://doi.org/10.17221/40/ 2017-VETMED.

Bauman, D. E., and W. B. Currie. 1980. Partitioning of nutrients during pregnancy and lactation: A review of mechanisms involving homeostasis and homeorhesis. J. Dairy Sci. 63:1514-1529. https:// doi.org/10.3168/jds.S0022-0302(80)83111-0.

Bell, A. W. 1995. Regulation of organic nutrient metabolism during transition from late pregnancy to early lactation. J. Anim. Sci. 73:2804-2819. https://doi.org/10.2527/1995.7392804x.

Bell, A. W., C. L. Ferrell, and H. C. Freetly. 1993. Pregnancy and fetal metabolism. 2nd ed. J. Dijkstra, J. M. Forbes, and J. France, ed. CABI Publishing, Wallingford.

Bell, A. W., M. B. Rymph, R. Slepetis, W. A. House, and R. A. Ehrhardt. 1992. Net nutrient requirements for conceptus growth in Holstein cows-implications for dry cow feeding. Page 102 in Proceedings-Cornell Nutrition Conference for Feed Manufacturers.

Castro, N., J. Capote, R. M. Bruckmaier, and A. Argüello. 2011. Management effects on colostrogenesis in small ruminants: A review. J. Appl. Anim. Res. 39:85-93. https://doi.org/10.1080/09712119 .2011 .581625 .
Duarte, M. S., M. P. Gionbelli, P. V. R. Paulino, N. V. L. Serao, T. S. Martins, P. I. S. Totaro, C. A. Neves, S. C. Valadares Filho, M. V. Dodson, M. Zhu, and M. Du. 2013. Effects of maternal nutrition development of gastrointestinal tract of bovine fetus at different stages of gestation. Livest. Sci. 153:60-65. https://doi.org/10 $.1016 /$ j.livsci.2013.01.006.

Ferrell, C. L., W. N. Garrett, and N. Hinman. 1976a. Estimation of body composition in pregnant and non-pregnant heifers. J. Anim. Sci. 42:1158-1166. https://doi.org/10.2527/jas1976.4251158x.

Ferrell, C. L., W. N. Garrett, and N. Hinman. 1976b. Growth, development and composition of the udder and gravid uterus of beef heifers during pregnancy. J. Anim. Sci. 42:1477-1489. https://doi .org/10.2527/jas1976.4261477x.

Godden, S. 2008. Colostrum management for dairy calves. Vet. Clin. North Am. Food Anim. Pract. 24:19-39. https://doi.org/10.1016/ j.cvfa.2007.10.005.

Greseth, N. P., M. S. Crouse, K. J. McLean, M. R. Crosswhite, N. N. Pereira, A. K. Ward, L. P. Reynolds, C. R. Dahlen, B. W. Neville, P. P. Borowicz, and J. S. Caton. 2017a. Effects of maternal nutrition on fructose and expression of the fructose transporter GLUT5 in bovine tissues and fluids from days 16 to 50 of gestation. J. Anim. Sci. 95(Suppl_2):191. https://doi.org/10.2527/asasmw.2017 .394 .

Greseth, N. P., M. S. Crouse, K. J. McLean, M. R. Crosswhite, N. N. Pereira, A. K. Ward, L. P. Reynolds, C. R. Dahlen, B. W. Neville, P. P. Borowicz, and J. S. Caton. 2017b. The effects of maternal nutrition on messenger ribonucleic acid expression of neutral and acidic amino acid transporters in bovine uteroplacental tissues from day sixteen to fifty of gestation. J. Anim. Sci. 95:4668-4676.

Mann, G. E., G. E. Lamming, R. S. Robinson, and D. C. Wathes. 1999. The regulation of interferon-tau production and uterine hormone receptors during early pregnancy. J. Reprod. Fertil. Suppl. $54: 317-328$

Marcondes, M. I., A. L. Silva, M. P. Gionbelli, and S. C. Valadares Filho. 2016. Exigências de energia para bovinos de corte. 3rd ed. S. C. Valadares Filho, L. F. Costa e Silva, M. P. Gionbelli, P. P. Rotta, M. I. Marcondes, M. L. Chizzotti, and L. F. Prados, ed. Suprema Gráfica Ltda, Viçosa, MG, Brazil.

NRC. 2001. Nutrient Requirements of Dairy Cattle. 7th rev. ed. Natl. Acad. Press, Washington, DC.

Nürnberg, K., J. Wegner, and K. Ender. 1998. Factors influencing fat composition in muscle and adipose tissue of farm animals. Livest. Prod. Sci. 56:145-156. https://doi.org/10.1016/S0301 -6226(98)00188-2.

Owens, F. N., P. Dubeski, and C. F. Hanson. 1993. Factors that alter the growth and development of ruminants. J. Anim. Sci. 71:31383150. https://doi.org/10.2527/1993.71113138x.

Owens, F. N., D. R. Gill, D. S. Secrist, and S. W. Coleman. 1995. Review of some aspects of growth and development of feedlot cattle. J. Anim. Sci. 73:3152. https://doi.org/10.2527/1995.73103152x.

Peter, A. T. 2013. Bovine placenta: A review on morphology, components, and defects from terminology and clinical perspectives. Theriogenology 80:693-705. https://doi.org/10.1016/j.theriogenology .2013.06.004.

Plath, A., R. Einspanier, F. Peters, F. Sinowatz, and D. Schams. 1997. Expression of transforming growth factors alpha and beta- 1 messenger RNA in the bovine mammary gland during different stages of development and lactation. J. Endocrinol. 155:501-511. https:/ /doi.org/10.1677/joe.0.1550501.

Plath-Gabler, A., C. Gabler, F. Sinowatz, B. Berisha, and D. Schams. 2001. The expression of the IGF family and GH receptor in the bovine mammary gland. J. Endocrinol. 168:39-48. https://doi.org/ 10.1677/joe.0.1680039.

Rotta, P. P., S. C. Valadares Filho, T. R. S. Gionbelli, L. F. Costa e Silva, T. E. Engle, M. I. Marcondes, M. M. Campos, A. C. B. Menezes, and A. A. G. Lobo. 2015a. Effects of day of gestation and feeding regimen in Holstein $\times$ Gyr cows: II. Maternal and fetal visceral organ mass. J. Dairy Sci. 98:3211-3223. https://doi.org/ 10.3168/jds.2014-8282.

Rotta, P. P., S. C. Valadares Filho, T. R. S. Gionbelli, L. F. Costa e Silva, T. E. Engle, M. I. Marcondes, S. E. F. Guimarães, C. S. 
Nascimento, B. C. Carvalho, F. A. S. Silva, and J. R. S. Oliveira. 2015b. Effects of day of gestation and feeding regimen in Holstein $\times$ Gyr cows: III. Placental adaptations and placentome gene expression. J. Dairy Sci. 98:3224-3235. https://doi.org/10.3168/jds 2014-8283.

Rotta, P. P., S. C. Valadares Filho, T. R. S. Gionbelli, L. F. Costa e Silva, T. E. Engle, M. I. Marcondes, F. S. Machado, F. A. C. Villadiego, and L. H. R. Silva. 2015c. Effects of day of gestation and feeding regimen in Holstein $\times$ Gyr cows: I. Apparent total-tract digestibility, nitrogen balance, and fat deposition. J. Dairy Sci. 98:3197-3210. https://doi.org/10.3168/jds.2014-8280.

Silva, H. G. de O. 2010. Desenvolvimento do útero grávido e da glândula mamária e mudanças corporais em cabras leiteiras durante a gestação. PhD Thesis. Universidade Estadual Paulista, Faculdade de Ciências Agrárias e Veterinárias, Jaboticabal.

Toniollo, G. H., and W. R. R. Vicente. 1995. Manual de Obstetrícia Veterinária. Varela, São Paulo, Brazil.

Van Eetvelde, M., M. M. Kamal, M. Hostens, L. Vandaele, L. O. Fiems, and G. Opsomer. 2016. Evidence for placental compensation in cattle. Animal 10:1342-1350. https://doi.org/10.1017/ S1751731116000318.

Vann, R. C., J. W. Holloway, G. E. Carstens, M. E. Boyd, and R. D. Randel. 1995. Influence of calf genotype on colostral immunoglobulins in Bos taurus and Bos indicus cows and serum immunoglobulins in their calves. J. Anim. Sci. 73:3044-3050. https://doi .org/10.2527/1995.73103044x.
Vonnahme, K. A., A. R. Tanner, and M. A. V. Hildago. 2018. Effect of maternal diet on placental development, uteroplacental blood flow, and offspring development in beef cattle. Pages 912-922 in 10th International Ruminant Production Symposium.

Wiltbank, M. C., G. M. Baez, A. Garcia-Guerra, M. Z. Toledo, P. L. J. Monteiro, L. F. Melo, J. C. Ochoa, J. E. P. Santos, and R. Sartori. 2016. Pivotal periods for pregnancy loss during the first trimester of gestation in lactating dairy cows. Theriogenology 86:239-253. https://doi.org/10.1016/j.theriogenology.2016.04.037.

Yan, L., R. Robinson, Z. Shi, and G. Mann. 2016. Efficacy of progesterone supplementation during early pregnancy in cows: A metaanalysis. Theriogenology 85:1390-1398. https://doi.org/10.1016/j .theriogenology.2015.12.027.

\section{ORCIDS}

Anna L. L. Sguizzato ๑ https://orcid.org/0000-0003-3867-971X Marcos I. Marcondes (ㄷ https://orcid.org/0000-0003-4843-2809 Tammi L. Neville @ https://orcid.org/0000-0001-6642-9449 Fernanda S. Machado @ ittps://orcid.org/0000-0002-7380-4961 Polyana P. Rotta @ https://orcid.org/0000-0002-1185-8120 